\title{
Hazardous waste management in Egypt: performance indicators for industry
}

\author{
A. R. Ramadan ${ }^{1}$ \& Y. Sherif ${ }^{2}$ \\ ${ }^{1}$ Chemistry Department, American University in Cairo, Egypt \\ ${ }^{2}$ Environics, Cairo, Egypt
}

\begin{abstract}
Hazardous waste (HW) management represents a central aspect of the environmental performance of industrial establishments in Egypt. In response to the need for monitoring this performance and the progress of industries in managing their HW, sets of HW indicators have been developed within the larger scope of environmental performance indicators for industry. The HW indicators address three themes: compliance to regulations, HW generation, and cleaner production. These indicators are presented together with the bases for their development. Opportunities for their use, particularly as a decision-making support tool, and challenges facing their application, are also presented.
\end{abstract}

Keywords: hazardous waste management, industry, indicators, Egypt.

\section{Introduction}

Industrial activities in Egypt have developed to constitute a significant portion of the economy, contributing 35\% of the GDP. The industrial sector comprises more than 271,000 establishments, employing $25 \%$ of the workforce [1]. However, these establishments present the largest contributors to environmental pollution, particularly with regards to the generation of hazardous waste (HW) [2]. In this respect, proper management of HW presents one of the priority lines of action for the improvement of the environmental performance of industries [3]. This is addressed through different initiatives encompassing the promotion of waste minimization, cleaner production, as well as developing the capacities of industrial establishments with regards to HW management practices [4-6]. With the purpose of monitoring the progress of industries in this respect, a number of indicators have been developed. They are part of a larger set of 
environmental performance indicators for industries. This paper presents these HW management indicators, the bases on which they were developed, as well as opportunities and challenges for their use.

\section{Hazardous waste management in Egyptian industries}

In Egypt, HW was recognized for the first time as a source of environmental degradation with the issuance of the Egyptian Law 4 for the Environment, its Executive Regulations [7]. Since then, the implementation of proper HW management practices, though identified as a priority on the national level [8], has faced a number of challenges [4]. For the industrial sector, these challenges encompass, on the one hand, the absence of proper treatment and disposal facilities for generated $\mathrm{HW}$, and on the other, a sense of ambiguity regarding HW and its integrated management system comprising complementary "on-site" and "off-site" practices [4, 6].

Different initiatives have been carried out to address these challenges: an industrial HW treatment and disposal facility was established in Alexandria (the Nasreya Centre) and has been in full operation since 2005. Moreover, the establishment of further facilities is underway in the Suez area, as well as in Greater Cairo. On the other hand, programs addressing the capacity and awareness needs for HW management within this sector have been implemented [6]. In consequence, the need to monitor the progress of Egyptian industries in managing their HW evolved. This occurred within the larger context of monitoring the environmental performance of industries in Egypt [3].

\section{The overall context: indicators for the environmental performance of industries in Egypt}

Sets of indicators have been developed for monitoring the environmental performance of Egyptian industries, in order to assist in the identification of deficiencies and opportunities for improvement. In this respect, three sets of indicators have been developed: compliance indicators monitoring the compliance with regulations; pollution indicators monitoring pollution emissions of industrial establishments (air, water, and waste); and cleaner production indicators, monitoring the progress of industries towards cleaner production and waste minimization [3]. These indicator sets take into account existing international guidelines and indicator systems [9-16], adapting them to local specificities and needs.

\section{Hazardous waste indicators for industries in Egypt: an overview}

Within the context of monitoring the environmental performance of industrial establishments, sets of indicators were developed to monitor practices of HW 
management, namely for the three areas of compliance to existing regulations, pollution emissions expressed as waste generation, and cleaner production expressed as hazardous raw material consumption and waste minimization. These indicators are calculated on the level of the industrial subsector in order to allow the assessment of the performance of individual subsectors with regards to each of the three different areas. This renders comparisons between subsectors possible, which is valuable for identifying areas of strengths and priorities for action, as well as for assisting in the determination of the possible factors influencing the performance in HW management (e.g. sizes of establishments, technologies commonly used, geographical aggregations, etc.), together with the significance of the respective contributions of these factors on performance. It is important to note that the developed HW indicators are applicable to industrial establishments generating $\mathrm{HW}$ as per the HW list issued by the Egyptian Ministry of Industry in this regard [17].

\subsection{Compliance indicators}

Egyptian legislation addressing HW management is comprehensive with regards to the different safe practices for HW from the point of generation till final disposal [7]. This legislation presents the framework for the HW management to which industrial establishments in Egypt are to abide. In this respect, the compliance indicators monitor the progress of these establishments in implementing the stipulations set in this legislation.

To this end, a three-tiered indicator set was developed. The first tier addresses the primary practice of HW identification, essential for the implementation of all subsequent HW practices. The second tier addresses "basic HW management" constituted of HW identification, HW segregation, and proper on-site storage. The third tier addresses "advanced HW management" constituted by HW identification, segregation, proper on-site storage, and proper clearance of HW by on-site treatment and/or off-site transportation to facilities licensed to receive HW [3]. Within this context, the progress of an industrial establishment in complying with HW regulations is reflected by its advancement from the first tier to the second and the third. Essential to the effectiveness of this system is the clear determination of whether a particular practice is implemented or not. In this regard, simple criteria are used, as detailed in section 5.1 .

\subsection{Pollution and cleaner production indicators}

These indicators are concerned with monitoring the generation of HW by industrial establishments on the one hand, and the consumption of hazardous substances (HS) as input material and HW minimization on the other hand. Though HW legislation in Egypt requires establishments generating HW to carry out waste minimization, no specifications are set on how this is to be carried out, nor are any quantitative targets indicated. In this respect, these indicators necessitate the use of benchmarks as references to compare with [3]. 


\section{Hazardous waste compliance indicators for industries in Egypt: details}

The compliance indicator set is composed of three indicators constituting a threetiered system.. Within this system, establishments falling within the scope of tier 2 , are also captured by tier 1 because their basic HW management practices incorporate $\mathrm{HW}$ identification. In turn, establishments falling within the scope of tier 3 are also captured by tiers 2 and 1. In other words, tier 1 represents the overall scope within which establishments carrying out one or more HW management practices fall. Within this overall scope, tiers 2 and 3 represent more limited scopes reflecting more advanced levels of compliance. This is schematically presented in fig. 1 .

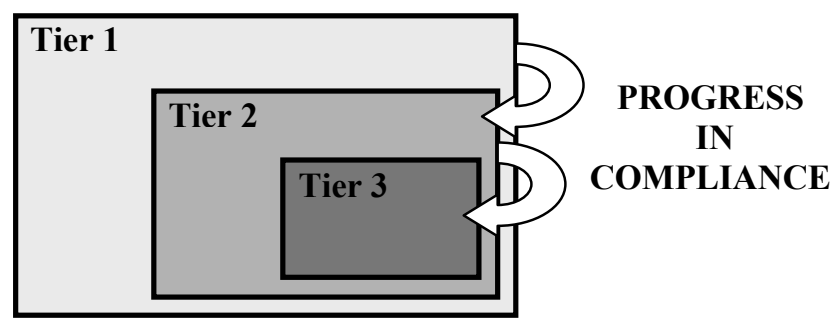

Figure 1: $\quad$ Schematic presentation of the three-tiered system.

An indicator has been developed for each tier to capture the establishments falling within it. The determination of whether an establishment is carrying out a particular HW management practice or not is based on a number of criteria, as detailed below.

\subsection{Criteria for the assessment of implementation of HW management practices}

The extent of implementation of HW management in industrial establishments is monitored through the practices of $\mathrm{HW}$ identification, HW segregation, proper on-site storage of HW, and proper clearance by on-site treatment and/or off-site transportation to facilities licensed to accept HW. In this respect, each of these practices can be carried out with different degrees of effectiveness. Trying to capture this continuum through indicators would necessitate assessment criteria too complex for the system, particularly at its initial phase. Consequently, what is of interest at this phase is to determine whether a practice is implemented or not, i.e. limiting the assessment for implementation to a binary outcome: "true" if it is implemented, and "false" if it is not. To this end, simple criteria for each practice were developed for this assessment to be carried out reproducibly.

For HW identification, a HW-generating establishment is considered as carrying out HW identification when a HW register is present, and the register is updated with HW generation data (types and amounts). This register is a requirement of national $\mathrm{HW}$ regulations, which specify that any $\mathrm{HW}$-generating 
entity is to keep a register with data for the types of generated HW, identified as per HW lists issued by concerned regulatory bodies (this is the Ministry of Industry for industrial establishment), quantities, together with information about on-site storage practices carried out, details of on-site treatment, off-site transportation as well as final off-site destinations.

For HW segregation, a HW-generating establishment is considered as carrying out HW segregation when all identified HW generated is segregated from other non-hazardous waste streams. This segregation allows the subsequent management of the HW separately from non-hazardous wastes.

For on-site storage, a HW-generating establishment is considered as carrying out on-site storage of HW when a separate location, having a controlled access and the necessary safety precautions as specified by national regulations, is identified on-site for HW storage, and the identified HW generated and segregated is only stored at this location.

For HW clearance, a HW-generating establishment is considered as carrying out proper HW clearance when either on-site treatment is carried out using operations approved by the competent regulatory authority, as stipulated by national regulations, or off-site transportation is carried out using vehicles meeting the specifications set by national regulations, and entities responsible for the transportation are licensed to do so, and the final destinations of transported HW are facilities licensed to receive this waste.

\subsection{The HW compliance indicators}

Three indicators constitute the compliance indicator set addressing tiers 1 to 3 as follows:

Name: Compliance-T1

Type: State

Definition: This is the measure of the number of HW-generating industrial establishments carrying out HW identification, expressed as a percentage of the total number of HW-generating industrial establishments within an industrial subsector.

Unit of measurement: percentage

Calculation:

Compliance $-\mathrm{T} 1=\frac{\text { no. of establishments with HW identification }}{\text { total no. of HW generating industrial establishments }} \times 100$

Name: Compliance-T2

Type: State

Definition: This is the measure of the number of HW-generating industrial establishments carrying out "basic HW management", expressed as a percentage of the total number of $\mathrm{HW}$-generating industrial establishments within an industrial subsector.

Unit of measurement: percentage

Calculation:

Compliance $-\mathrm{T} 2=\frac{\text { no. of establishments with basic HW management }}{\text { total no. of HW generating industrial establishments }} \times 100$ 
Name: Compliance-T3

Type: State

Definition: This is the measure of the number of HW-generating industrial establishments carrying out "advanced HW management", expressed as a percentage of the total number of $\mathrm{HW}$-generating industrial establishments within an industrial subsector.

\section{Unit of measurement: percentage}

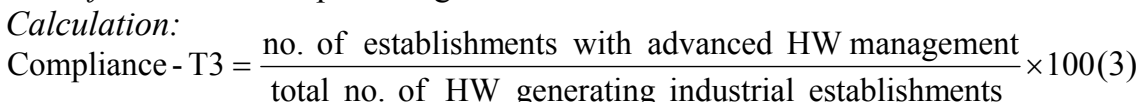

For each of these indicators, the required data are available at the level of the establishment, primarily in HW registers.

With regard to responsiveness, increases in the values of these indicators reflect improvements in compliance with HW management regulations. The inclusiveness of tier 3 in tier 2, and of tier 2 in tier 1 ensures that the responsiveness of these indicators is straightforward: migration of establishments from one tier to a higher one does not decrease the value of the lower tier indicator. This renders the interpretation of these indicators clear-cut: increase in values means improvement in compliance, and vice versa.

To obtain values for each of these indicators for the industrial sector as whole, their values for individual industrial subsectors are combined as per the following equation:

$$
\text { Compliance-T } x=\frac{\sum a \times \text { no. of establishments in industrial subsector (n) }}{\text { total no. of HW generating industrial establishments }}
$$

Where $x$ can either be 1, 2 or 3 depending on the tier this is calculated for, and $a$ presents the percentage of establishments in an industrial sector (n) carrying out the HW management practices in questions, i.e. HW identification for tier 1 , "basic HW management" practices for tier 2, and "advanced HW management" practices for tier 3 , as detailed in section 4.1. The summation is carried out over all industrial subsectors resulting in one value for industry.

\section{HW pollution and cleaner production indicators for industries in Egypt: details}

Pressures on the environment from industrial HW primarily result from HW generation, HW site contamination, as well as imports of HW [12, 14]. In Egypt, HW generation and site contamination with HW are the two significant factors, as the ban on importing HW, stipulated by national regulations, is effectively enforced. Site contamination by $\mathrm{HW}$ has only come under investigation very recently, and though receiving increasing attention, remains largely unidentified nationally. Consequently, the area of priority for monitoring the environmental pressure of industrial $\mathrm{HW}$, at the initial phase of the system, entails waste generation.

With regards to cleaner production, two factors are identified for monitoring the performance of industries concerning HW. These comprise the consumption 
of HS as input material, and HW minimization. The former is included based on the rationale that the consumption of HS as input material does result in the generation of HW composed of the packaging material and empty containers of these substances, and to a lesser extent of outdated materials, waste resulting from spillages, mishandling etc. [3].

\subsection{HW generation indicator}

Name: HW Generation

Type: Pressure

Definition: This is the measure of the amount of HW generated per annum for an industrial subsector, expressed in tons.

Unit of measurement: tons/annum

Calculation:

$$
\text { HW Generation }=\sum \text { tons of HW generated }
$$

The required data are available at the level of the establishment from the HW register. However, data reliability for this indicator is low, because quantities of generated HW registered are frequently estimates. It is important to note that available data correspond to actual generation amounts, as estimated at sources of generation, rather than the commonly used amounts collected by contractors [12]. An increase in the value of this indicator corresponds to an increased pressure on the environment.

To obtain the amount of HW generated by industry, the values of this indicator for individual industrial subsectors is summed over all industrial subsectors.

\subsection{Cleaner production indicators}

The cleaner production indicators pertaining to HW, incorporate the use of benchmarks, which vary significantly between industrial subsectors (their variation within a subsector can also be significant, depending on the types of technologies used). In this respect, benchmarks for HS consumption as input material correspond to the average consumption value, normalized to the ton of product, within a subsector in Egypt. Benchmarks for HW generation correspond to the average generation value, also normalized to the ton of product, within a subsector in Egypt. Negative deviations from these benchmarks reflect cleaner production, while positive deviations reflect the need for cleaner production. These average consumption/generation values have been found to be significantly higher than international values, and their use to assess cleaner production in Egyptian industries inherently incorporates a cutback-factor for the need of cleaner production [3]. The calculation of indicators for HS consumption and HW generation per industrial subsector rely on calculations carried out at the establishment level, according to the following:

Name: CP-HS-E

Type: State 
Definition: This is the measure of deviation of the normalized consumption of hazardous substances at the establishment level relative to the benchmark within the specific industrial subsector of the establishment, expressed as a percentage. The normalization is carried out to the ton of product.

\section{Unit of measurement: percentage}

\section{Calculation:}

$$
\mathrm{CP}-\mathrm{HS}-\mathrm{E}=\frac{\text { normalized consumption of HS }-\mathrm{BM}}{\mathrm{BM}} \times 100
$$

where $\mathrm{BM}$ is the benchmark for the specific industrial sector, entailing the average consumption of HS, in Egypt, normalized to the ton of product.

Name: CP-HW-E

Type: State

Definition: This is the measure of deviation of the normalized generation of HW at the establishment level relative to the benchmark within the specific industrial subsector of the establishment, expressed as a percentage. The normalization is carried out to the ton of product.

\section{Unit of measurement: percentage}

\section{Calculation:}

$$
\mathrm{CP}-\mathrm{HW}-\mathrm{E}=\frac{\text { normalized generation of } \mathrm{HW}-\mathrm{BM}}{\mathrm{BM}} \times 100
$$

where $\mathrm{BM}$ is the benchmark for the specific industrial sector, entailing the average generation of HW, in Egypt, normalized to the ton of product.

With regards to responsiveness of these establishment-level indicators, negative values of the indicator demonstrate performance better than the average within the industrial subsector in question. The lower the value of the indicator in this regard, the better is the performance. On the other hand, positive values demonstrate performances worse that the average within the industrial subsector in question. The higher the value the worse is the performance.

To capture the status of cleaner production pertaining to $\mathrm{HW}$ within an industrial subsector, the standard deviation $s$ from the benchmark (this benchmark is the average consumption of HS / generation of HW) is used to determine the percentage of facilities falling short of/exceeding the benchmark within ranges of $1 s, 2 s$, etc.

Name: CP-HS-ISS

Type: State

Definition: This is the percentage of establishments falling within a determined range of the benchmark regarding the consumption of HS.

\section{Unit of measurement: percentage}

\section{Calculation:}

$$
\mathrm{CP}-\mathrm{HS}-\mathrm{ISS}=\frac{\text { no. of establishments meeting the condition }}{\text { total no. of establishments }} \times 100
$$

where "the condition" corresponds to values of $1 s, 2 s$, etc.

Name: CP-HW-ISS

Type: State

This is the percentage of establishments falling within a determined range of the benchmark regarding the generation of $\mathrm{HW}$. 
Unit of measurement: percentage

Calculation:

$$
\mathrm{CP}-\mathrm{HW}-\mathrm{ISS}=\frac{\text { no. of establishments meeting the condition }}{\text { total no. of establishments }} \times 100
$$

where "the condition" corresponds to values of $1 s, 2 s$, etc.

These indicators capture the distribution of individual establishment performances in relation to the corresponding benchmarks. Values for conditions below the benchmarks (i.e. $-1 s,-2 s$, etc.) demonstrate that numbers of establishments are performing better than the average. On the other hand, values for conditions above the benchmarks (i.e. $+1 s,+2 s$, etc.) demonstrate that numbers of establishments are performing worse than the average.

\section{Opportunities and challenges}

At the initial stage of applying sets of indicators for monitoring HW management in industries, the primary need for these indicators is to assess the global situation, reflecting its improvement or deterioration. In this respect, the indicators capture the progress of industries in complying with existing regulations, as well as their status with regards to the generation of HW, consumption of HS, and HW minimization. These indicators serve in providing a very useful input to decision making, particularly concerning interventions necessary for improving HW management by industries: for example, projections for needed HW management services (transportation, treatment, disposal, etc.), for improving the effectiveness of enforcement efforts, for technical support and capacity building, as well as for efforts in addressing gaps in regulations.

The three HW themes the indicators address (compliance to regulations, HW generation and HS cleaner production) are complementary and interrelated. In this respect synergies between them can be very valuable. For example: projections for needed HW management services would be more effective if the overall progress of establishments in complying to regulations, as well as cleaner production efforts, are taken into consideration; progress in cleaner production efforts, reflected by the variation in HW generation, can only be effectively assessed if the status of compliance to regulations is taken into account; etc.

Challenges facing the use of these indicators are primarily concerned with data availability and quality, common obstacles in indicator systems $[10-13,16]$. Data required for the HW indicators presented here are available at the establishment level, where they are recorded in the HW registers. However, their generation relies on self-monitoring activities, for which industries in Egypt generally need more guidance and higher regulatory pressure in order to improve concurrence with actual discharges and practices [3]. Poor data quality can give rise to significant fluctuations of indicator values irrespectively from actual variations of the issues monitored. This can lead to a reduction of the sensitivity of indicator responsiveness.

Data collection is a difficult task, because no reporting mechanisms are in place to ensure the smooth extraction of data from establishments. In addition, 
sharing data with regulatory bodies is still largely considered with suspicion. In this respect, obtaining the needed data primarily requires visits to the individual industrial establishment take place. Though inspection activities have been used to this end, inspections target non-representative groups of establishments, usually focusing on those with violations and/or prone to non-compliance [3], resulting in non-representative data. To this end, surveys have been used [18, 19], and data collected from representative samples of establishments normalized and extrapolated. This has led to results reflecting the global situation, but which, however, do not reveal all its aspects.

\section{Conclusion}

With the purpose of monitoring the performance of Egyptian industries in managing their HW, a number of HW indicators have been developed within the larger scope of environmental performance indicators for industry. These indicators serve in providing needed feedback to decision making in Egypt, and synergies between them represent valuable opportunities for detailed assessment of different aspects of HW management in industries. However, a major challenge to the use of these indicators encompasses data availability and quality. However, it is believed that as the indicators are regularly used as a support tool to decision making, perceptible improvements of HW management in Egypt would take place. These improvements would in turn lead to improved data quality and availability, which would feed back into the indicator calculations, triggering a continued cycle of improved accuracy of indicator values, getting to more closely reflect the actual situation with its different aspects. Improved data would also allow the evolution of the system to address further aspects of HW management, monitoring details of implementation of different practices, and determining how well a practice is carried out, and/or how effective it is serving its purpose.

\section{References}

[1] Arab Republic of Egypt, Country Environmental Analysis (1992-2002), World Bank, Report No 31993-EG, 2005.

[2] Egyptian Pollution Abatement Project, Hazardous Waste Management Manual for Industry, Egyptian Environmental Affairs Agency, 2003.

[3] Egyptian Pollution Abatement Project, Environmental Performance Indicators for Industry, Egyptian Environmental Affairs Agency, 2004.

[4] Ramadan, A.R., Nadim A.H., Hazardous Waste Management in Egypt: Status and Challenges, Proc. of Waste Management and the Environment II, eds. V. Popov, H. Itoh, C.A. Brebbia and S. Kungolos, WIT Press: Southampton and Boston, pp. 125-135, 2004.

[5] Egyptian Pollution Abatement Project, Strategy and Action Plan for Cleaner Production in Egyptian Industry, Egyptian Environmental Affairs Agency, 2004. 
[6] Ramadan, A.R., Nadim A.H., Hazardous Waste Management: Educating Industrial Communities in Egypt, Proc. of Waste Management and the Environment III, eds. V. Popov, A.G. Kungolos, C.A. Brebbia and H. Itoh, WIT Press: Southampton and Boston, pp. 479-488, 2006.

[7] Executive Regulations of Law 4/1994 for the Environment, Chapter 2, 1995.

[8] National Environmental Action Plan (NEAP), Egyptian Environmental Affairs Agency, 2002.

[9] Bell, S., Morse, S., Sustainable Indicators, Measuring the Immeasurable, Earthscan Publications Ltd, London, 1999.

[10] Berkhout, F., Hertin, J., Azzone, G., Carlens, J., Drunen, M., Jasch, C., Noci, G., Olsthoorn, X., Tyteca, D., Van Der Woerd, F., Wagner, M., Wehrmeyer, W., Wolf, O., Measuring the Environmental Performance of Industry, Final Report of Project MEPI (ENV4-CT97-0655), Environment and Climate Research Programme, European Commission (EC), Brussels, 2001.

[11] Brodersen, J., Challenges in developing indicators on hazardous waste. Working paper No 33, Conference of European Statisticians, Ottawa, 2001.

[12] Commission of Sustainable Development Theme Indicator Framework, United Nations Department of Economic and Social Affairs, Division for Sustainable Development, 2001.

[13] Environmental Performance Indicators Guidelines for Organizations. Ministry of Environment, Government of Japan, 2003.

[14] Granados, A.J., Peterson, P.J., Hazardous waste indicators for national decision makers. Journal of Environmental Management, 55, pp. 249-263, 1999.

[15] IChem. The sustainability metrics: sustainable development progress metrics recommended for use in the process industries. Warwickshire: Institute of Chemical Engineers, 2002.

[16] OECD Key Environmental Indicators, OECD Environment Directorate, Paris, 2004.

[17] Egyptian Ministerial Decree 65, Ministry of Industry, 2002.

[18] Industrial Hazardous Waste Survey in Greater Cairo Region, Egyptian Environmental Affairs Agency, 2006.

[19] Suez Canal Regional Branch Office. Alternatives for Hazardous Waste Management in Suez - Part I, Egyptian Environmental Affairs Agency, 2005 . 